\title{
Clinical Course of Hepatitis B Viral Infection in Patients Undergoing Anti-Tumor Necrosis Factor a Therapy for Inflammatory Bowel Disease
}

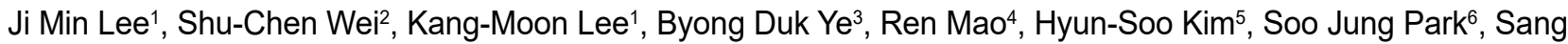 \\ Hyoung Park ${ }^{3}$, Eun Hye Oh ${ }^{3,7}$, Jong Pil Im ${ }^{8}$, Byung Ik Jang ${ }^{9}$, Dae Bum Kim ${ }^{1}$, and Ken Takeuchi ${ }^{10}$ \\ ${ }^{1}$ Department of Internal Medicine, St. Vincent's Hospital, College of Medicine, The Catholic University of Korea, Seoul, Korea, \\ ${ }^{2}$ Department of Internal Medicine, National Taiwan University Hospital, Taipei, Taiwan, ${ }^{3}$ Department of Gastroenterology and \\ Inflammatory Bowel Disease Center, Asan Medical Center, University of Ulsan College of Medicine, Seoul, Korea, ${ }^{4}$ Department of \\ Internal Medicine, First Affiliated Hospital, Sun Yat-sen University, Shanghai, China, ${ }^{5}$ Department of Internal Medicine and Institute of \\ Lifelong Health, Yonsei University Wonju College of Medicine, Wonju, ${ }^{6}$ Department of Internal Medicine, Yonsei University College of \\ Medicine, Seoul, ${ }^{7}$ Department of Gastroenterology, Haeundae Paik Hospital, Inje University College of Medicine, Busan, ${ }^{8}$ Department \\ of Internal Medicine, Seoul National University College of Medicine, Seoul, ${ }^{9}$ Department of Internal Medicine, Yeungnam University \\ College of Medicine, Daegu, Korea, and ${ }^{10}$ Department of Internal Medicine, Toho University Sakura Medical Center, Sakura, Japan
}

\section{Article Info}

Received February 22, 2021

Revised June 17, 2021

Accepted June 29, 2021

Published online October 1, 2021

\section{Corresponding Author}

Kang-Moon Lee

ORCID https://orcid.org/0000-0003-2850-4553

E-mail drmaloman@catholic.ac.kr

\section{Byong Duk Ye}

ORCID https://orcid.org/0000-0001-6647-6325

E-mail bdye@amc.seoul.kr

Ji Min Lee and Shu-Chen Wei contributed equally to this work as first authors.
Background/Aims: Little is known about the clinical course of hepatitis B virus (HBV)-infected patients undergoing anti-tumor necrosis factor $\alpha$ (TNF- $\alpha$ ) therapy for inflammatory bowel disease (IBD). We aimed to investigate the clinical course of HBV infection and IBD and to analyze liver dysfunction risks in patients undergoing anti-TNF- $\alpha$ therapy.

Methods: This retrospective multinational study involved multiple centers in Korea, China, Taiwan, and Japan. We enrolled IBD patients with chronic or resolved HBV infection, who received anti-TNF- $\alpha$ therapy. The patients' medical records were reviewed, and data were collected using a web-based case report form.

Results: Overall, 191 patients (77 ulcerative colitis and 114 Crohn's disease) were included, $28.3 \%$ of whom received prophylactic antivirals. During a median follow-up duration of 32.4 months, $7.3 \%$ of patients experienced liver dysfunction due to HBV reactivation. Among patients with chronic HBV infection, the proportion experiencing liver dysfunction was significantly higher in the non-prophylaxis group ( $26 \%$ vs $8 \%, p=0.02)$. Liver dysfunction occurred in one patient with resolved HBV infection. Antiviral prophylaxis was independently associated with an $84 \%$ reduction in liver dysfunction risk in patients with chronic HBV infection (odds ratio, 0.16; 95\% confidence interval, 0.04 to $0.66 ; p=0.01$ ). The clinical course of IBD was not associated with liver dysfunction or the administration of antiviral prophylaxis.

Conclusions: Liver dysfunction due to HBV reactivation can occur in HBV-infected IBD patients treated with anti-TNF- $\alpha$ agents. Careful monitoring is needed in these patients, and antivirals should be administered, especially to those with chronic HBV infection. (Gut Liver 2022;16:396403)

Key Words: Hepatitis B virus; Reactivation; Inflammatory bowel disease; Anti-tumor necrosis factor alpha

\section{INTRODUCTION}

The incidence of both Crohn's disease (CD) and ulcerative colitis is increasing in Korea and other Asian countries, ${ }^{1-3}$ along with the usage of anti-tumor necrosis factor $\alpha$ (TNF- $\alpha)$ agents such as infliximab and adalimumab, which can induce remission or maintain stable disease activity in patients with inflammatory bowel disease (IBD) ${ }^{4-6}$

Hepatitis B virus (HBV) infection is endemic among the general population in East Asia, unlike in Western 
countries. The trends observed in the general population are also found in patients with IBD. ${ }^{8}$ A nationwide survey in Spain showed that both chronic and resolved HBV infections were observed in $8 \%$ of IBD patients. ${ }^{9}$ In a Korean study, the HBV infection rate in patients with IBD reached $34 \%{ }^{10}$ Therefore, the clinical course of patients with HBV infection, who undergo anti-TNF- $\alpha$ treatment appears to be an important issue in Asian countries.

Although the mechanisms underlying the association between anti-TNF- $\alpha$ therapy and HBV reactivation remain largely unknown, TNF- $\alpha$ is expected to suppress HBV replication by stimulating cytotoxic $\mathrm{T}$ cells. By blocking these cytokine-producing cells, anti-TNF- $\alpha$ agents can induce HBV reactivation. ${ }^{11,12}$ Advances in the understanding of HBV replication and covalently closed circular DNA regulation have provided an interesting explanation on how TNF- $\alpha$ and related cytokines play an important role in the regulation of covalently closed circular DNA function. In particular, similar to interferon- $\alpha / \gamma$, TNF- $\alpha$ can activate the apolipoprotein B messenger RNA editing catalytic polypeptide-like protein via a unique antiviral pathway, that causes degradation of covalently closed circular DNA in HBV-infected cells. ${ }^{13}$ Thus, blocking this endogenous antiviral pathway may result in higher HBV replication and reactivation. Some reports have described HBV reactivation after anti-TNF- $\alpha$ treatment for rheumatologic diseases in HBV-infected patients. ${ }^{14,15}$ Moreover, a recently published report from the United States demonstrated anti-TNF- $\alpha$ therapy to be an important risk factor for $\mathrm{HBV}$ reactivation in patients with chronic $\mathrm{HBV}$ infection. ${ }^{12}$ Thus, clinical guidelines strongly recommend screening and vaccination for $\mathrm{HBV}$ infection before initiating antiTNF- $\alpha$ treatment. ${ }^{16-18}$ However, data on the clinical course of Asian IBD patients with HBV infection undergoing anti-TNF- $\alpha$ therapy are scarce. Therefore, in this study, we investigated the clinical course of HBV infection and IBD, and analyzed the risks of liver dysfunction in Asian patients undergoing anti-TNF- $\alpha$ therapy.

\section{MATERIALS AND METHODS}

This was a retrospective, multinational, and multicenter study involving four Asian countries (Korea, China, Taiwan, and Japan). We included patients (age, 20 to 70 years) with IBD (either CD or ulcerative colitis, diagnosed based on clinical, endoscopic, radiographic, laboratory, and pathological findings ${ }^{19,20}$ ) along with either chronic (hepatitis B surface antigen-positive) or resolved (presence of hepatitis B core antibodies with or without hepatitis B surface antibodies) HBV infection, who had undergone
anti-TNF- $\alpha$ therapy between January 2004 and December 2013. We excluded patients with liver disease other than HBV (i.e., hepatitis $C$ virus infection, alcoholic liver disease, autoimmune liver disease, toxic hepatitis, and others) and those with incomplete or absent medical records. The researchers reviewed the medical records of patients and collected data using a web-based case report form. Clini$\mathrm{cal}$ and demographic data, including nationality, age, sex, smoking habit, date of IBD diagnosis, disease extent of ulcerative colitis, disease phenotype of $\mathrm{CD}$ according to the Montreal classification, ${ }^{21}$ use of anti-TNF- $\alpha$ agents and immunomodulators (such as azathioprine, 6-mercaptopurine, or methotrexate) for IBD treatment, and drugs used for antiviral prophylaxis were assessed. Laboratory data, including viral-load status and liver function test results, were also collected.

\section{Outcome measures}

The primary outcome measure of the study was liver dysfunction related to $\mathrm{HBV}$ reactivation. Liver dysfunction related to HBV reactivation was defined as a two-fold increase in the upper limit of normal serum alanine transaminase levels and $a \geq 2 \log (100$-fold) increase in HBV-DNA load compared with the baseline level, or the reappearance of HBV-DNA viremia in individuals who were previously aviremic. $^{22,23}$ The secondary outcome measures included risk factors of liver dysfunction and the clinical course of IBD. Virologic response was defined as the undetectability of serum HBV-DNA on a polymerase chain reaction assay. ${ }^{24}$ The clinical course of IBD was evaluated using data on disease relapse, surgery, and hospitalization.

\section{Statistical analysis}

Continuous variables were presented as the mean \pm standard deviation, and categorical variables were expressed as total numbers and percentages. We used the ttest and the Wilcoxon rank-sum test to analyze continuous variables and the chi-square test for univariate analyses. The logistic regression test was used to calculate odds ratios and 95\% confidence intervals to assess the risk factors for liver dysfunction related to HBV reactivation. The Kaplan-Meier survival curve analysis was used to estimate the cumulative probability of liver dysfunction related to HBV reactivation during anti-TNF- $\alpha$ treatment, and compare the liver dysfunction rates according to antiviral prophylaxis used. $\mathrm{p}$-values $<0.05$ were considered statistically significant. Statistical analyses were performed using IBM SPSS Statistics version 20.0 (IBM Corp., Armonk, NY, USA) software. 


\section{Ethical considerations}

The study was reviewed and approved by the Institutional Research Ethics Board of the Catholic University of

Table 1. Baseline Characteristics

\begin{tabular}{|c|c|}
\hline Characteristics & Total $(n=191)$ \\
\hline Patients with $C D$ & $114(60)$ \\
\hline Age at diagnosis, mean $\pm \mathrm{SD}, \mathrm{yr}$ & $37.5 \pm 12.9$ \\
\hline Age at starting anti-TNF-a, mean $\pm S D, y r$ & $43.0 \pm 12.6$ \\
\hline Male sex & $136(71)$ \\
\hline Smoking & $37(19)$ \\
\hline \multicolumn{2}{|l|}{ Extent of UC } \\
\hline E1/E2/E3/UK & $14(18) / 36(47) / 20(26) / 7(9)$ \\
\hline \multicolumn{2}{|l|}{ Disease phenotype of CD } \\
\hline L1/L2/L3/UK & $37(32) / 11(10) / 65(57) / 1(1)$ \\
\hline $\mathrm{B} 1 / \mathrm{B} 2 / \mathrm{B} 3 / \mathrm{UK}$ & $42(37) / 29(25) / 43(38) / 0$ \\
\hline Perianal disease & $54(28)$ \\
\hline \multicolumn{2}{|l|}{ Anti-TNF-a agents } \\
\hline Infliximab/adalimumab/golimumab & $143(75) / 43(23) / 5(2)$ \\
\hline \multicolumn{2}{|l|}{ Indication of anti-TNF-a } \\
\hline Steroid dependency & $43(23)$ \\
\hline Steroid refractoriness & $54(28)$ \\
\hline Perianal disease & $9(5)$ \\
\hline Immunomodulator refractoriness & $85(45)$ \\
\hline Concomitant immunomodulators & $124(65)$ \\
\hline HBsAg positive & $87(46)$ \\
\hline Anti-HBs positive & $88(46)$ \\
\hline HBeAg positive & $17(9)$ \\
\hline Anti-HBe positive & $54(28)$ \\
\hline Anti-HBc positive & $104(54)$ \\
\hline HBV DNA titer, mean $\pm S D, \log _{10}$ copies $/ \mathrm{mL}$ & $3.1 \pm .2 .3$ \\
\hline $\mathrm{AST}$, mean $\pm \mathrm{SD}, \mathrm{IU} / \mathrm{L}$ & $21 \pm 13$ \\
\hline$A L T$, mean $\pm S D, I U / L$ & $17 \pm 14$ \\
\hline Hemoglobin, mean $\pm S D, g / d L$ & $12.0 \pm 2.0$ \\
\hline Total bilirubin, mean $\pm S D, \mathrm{mg} / \mathrm{dL}$ & $0.8 \pm 2.0$ \\
\hline Prothrombin time, mean $\pm S D$, INR & $1.0 \pm 0.1$ \\
\hline Albumin, mean $\pm S D, g / d L$ & $3.7 \pm 0.7$ \\
\hline $\begin{array}{l}\text { Follow-up period after initiation of anti- } \\
\text { TNF-a, median (range), mo }\end{array}$ & $32.4(2-138)$ \\
\hline
\end{tabular}

Data are presented as the number (\%) unless otherwise indicated. $C D$, Crohn's disease; TNF, tumor necrosis factor; UC, ulcerative colitis; UK, unknown; HBsAg, hepatitis B surface antigen; anti-HBs, hepatitis B surface antibody; $\mathrm{HBeAg}$, hepatitis $B$ envelope antigen; anti-HBe, hepatitis $B$ envelope antibody; anti- $\mathrm{HBc}$, hepatitis $B$ core antibody; HBV, hepatitis B virus; AST, aspartate aminotransferase; $A L T$, alanine aminotransferase; INR, international normalized ratio.
Korea (IRB number: VC14RIGI0228). Informed consent was obtained from all study subjects.

\section{RESULTS}

\section{Demographic characteristics of the subjects}

A total of 191 IBD cases $(18,17,2$, and 154 from China, Taiwan, Japan, and Korea, respectively) were included. Among these, 60\% had CD. The patients were administered anti-TNF- $\alpha$ agents infliximab, adalimumab, or golimumab. Additionally, $65 \%$ of the patients were concomitantly treated with immunomodulators. The median duration of follow-up after starting anti-TNF- $\alpha$ therapy was 32.4 months (range, 2 to 138 months). Chronic HBV infection was diagnosed in 87 patients (46\%). The patient characteristics are summarized in Table 1.

\section{Prophylaxis against HBV reactivation}

Approximately $28.3 \%$ of patients (54/191) received prophylactic antiviral therapy, of whom $96 \%(52 / 54)$ had chronic HBV infection (Fig. 1). Prophylactic entecavir was administered to 30 out of 54 patients (56\%), tenofovir to nine out of 54 patients (16\%), lamivudine to nine out of 54 patients (16\%), and telbivudine to six out of 54 patients (12\%).

\section{Liver dysfunction related to HBV reactivation}

Liver dysfunction related to HBV reactivation was observed in $7.3 \%$ of patients (14/191) at follow-up. Liver dysfunction was significantly lower in the antiviral prophylaxis group than in the non-prophylaxis group with chronic HBV infection ( $26 \%$ vs $8 \%, p=0.02)$. Only one patient experienced liver dysfunction in the group with resolved infection (Table 2). No liver dysfunction occurred in patients with hepatitis B surface antibodies in the group with resolved infection $(0 / 87)$.

On Kaplan-Meier survival curve analysis, administration of antiviral prophylaxis was found to be significantly associated with a lower rate of liver dysfunction in patients with chronic HBV infection $(p=0.03)$. The cumulative

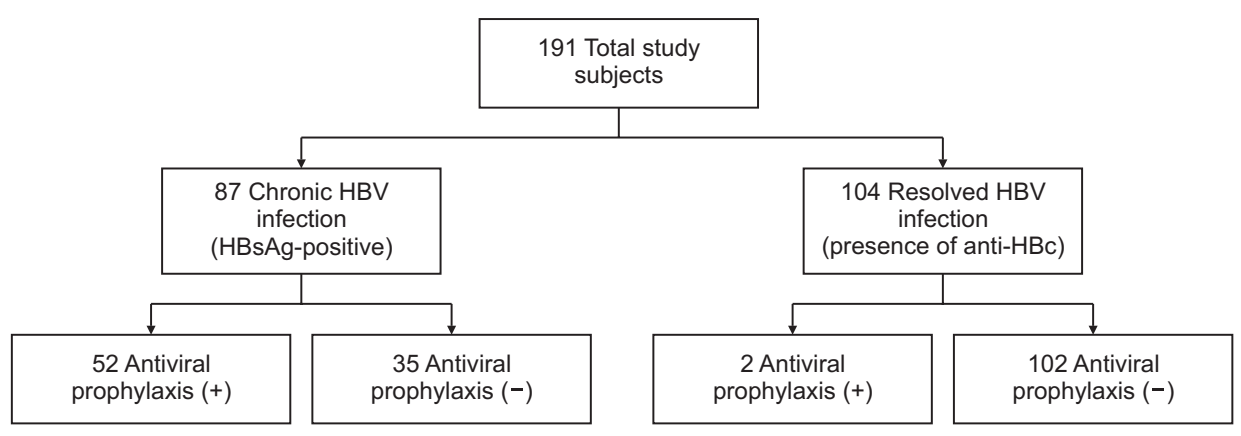

Fig. 1. Study flowchart. HBV, hepatitis B virus; HBsAg, hepatitis $B$ surface antigen; anti-HBc, hepatitis B core antibody. 
Table 2. Liver Dysfunction Rate According to Antiviral Prophylaxis

\begin{tabular}{lccc}
\hline & Prophylaxis (+) & Prophylaxis (-) & $p$-value \\
\hline Chronic HBV infection (HBsAg positive, $n=87)$ & $4 / 52(8)$ & $9 / 35(26)$ & 0.02 \\
Resolved HBV infection (presence of anti-HBc, $n=104)$ & $0 / 2(0)$ & $1 / 102(1)$ & 0.98 \\
\hline
\end{tabular}

Data are presented as the number/number (\%).

$\mathrm{HBV}$, hepatitis B virus; $\mathrm{HBsAg}$, hepatitis B surface antigen; anti-HBc, hepatitis B core antibody.

A

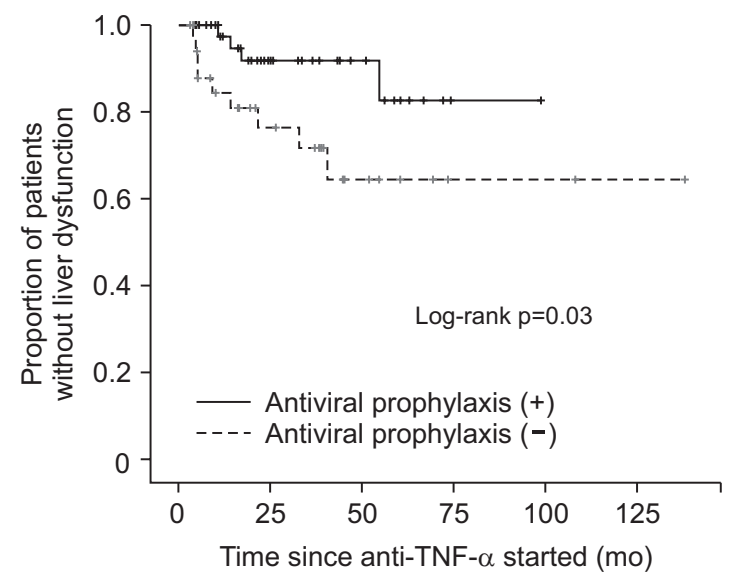

No. at risk

Prophylaxis (+) $52 \quad 23 \quad 11 \quad 1$

$\begin{array}{lllll}\text { Prophylaxis (-) } & 35 & 16 & 7 & 2\end{array}$
B

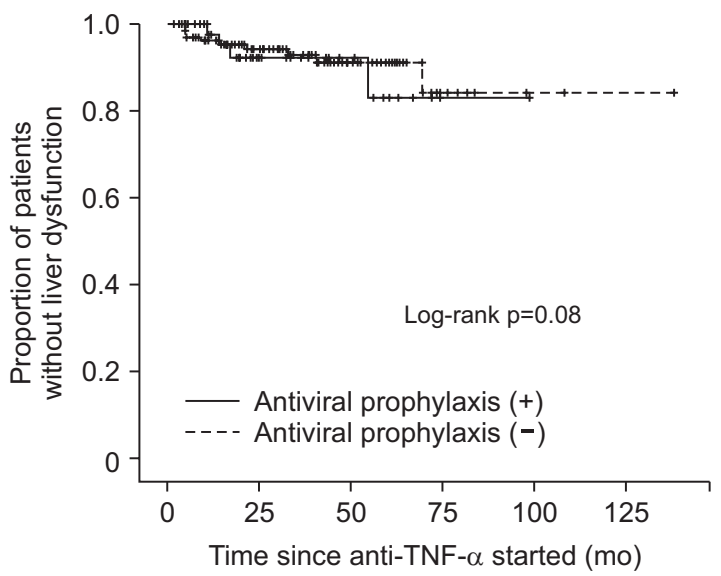

No. at risk

\begin{tabular}{lrrrr} 
Prophylaxis (+) & 54 & 24 & 11 & 1 \\
\hline Prophylaxis (-) & 137 & 83 & 37 & 8
\end{tabular}

Fig. 2. Liver dysfunction according to antiviral prophylaxis in patients with chronic hepatitis B virus infection (A) and in all study subjects (B). TNF, tumor necrosis factor.

Table 3. Risks for Liver Dysfunction due to Hepatitis B Virus Reactivation

\begin{tabular}{lccc}
\hline \multicolumn{1}{c}{ Parameter } & Liver dysfunction positive $(\mathrm{n}=14)$ & Liver dysfunction negative $(\mathrm{n}=177)$ & $\mathrm{p}$-value \\
\hline Crohn's disease & $8(57)$ & $106(60)$ & 0.18 \\
Male sex & $12(86)$ & $124(70)$ & 0.53 \\
Infliximab & $11(79)$ & $132(75)$ & 0.80 \\
Concomitant immunomodulators & $9(64)$ & $110(62)$ & 0.95 \\
HBsAg & $13(93)$ & $74(42)$ & $<0.001$ \\
Age at starting anti-TNF-a, yr & $45 \pm 17$ & $43 \pm 12$ & 0.49 \\
\hline
\end{tabular}

Data are presented as the number (\%) or mean \pm SD.

HBsAg, hepatitis B surface antigen; TNF, tumor necrosis factor.

probabilities of liver dysfunction in the antiviral prophylaxis group were $9.1 \%$ and $17.3 \%$ after 25 and 75 months, respectively; these probabilities were notably higher $(23.6 \%$ and $35.5 \%$ ) in the non-prophylaxis group (Fig. 2A). No significant difference was observed in the liver dysfunction rate related to the antiviral agent used, in any of the subjects $(\mathrm{p}=0.08)$ (Fig. 2B).

\section{Risk factors for liver dysfunction}

The presence of hepatitis B surface antigen was associated with liver dysfunction in all enrolled subjects ( $\mathrm{p}<0.001$ ). No significant difference was found with respect to other possible risk factors for HBV reactivation (Table 3). Only
Table 4. Logistic Regression Results for Predicting Liver Dysfunction in Patients with Chronic HBV Infection

\begin{tabular}{lcc}
\hline \multicolumn{1}{c}{ Parameter } & OR $(95 \% \mathrm{Cl})$ & $\mathrm{p}$-value \\
\hline Antiviral prophylaxis & $0.16(0.04-0.66)$ & 0.01 \\
Concomitant immunomodulators & $3.37(0.68-16.8)$ & 0.30 \\
HBV DNA titer $\left(\log _{10}\right.$ copies $\left./ \mathrm{mL}\right)$ & $0.81(0.60-1.08)$ & 0.20 \\
\hline
\end{tabular}

HBV, hepatitis B virus; OR, odds ratio; $\mathrm{Cl}$, confidence interval.

antiviral prophylaxis was independently associated with an $84 \%$ reduction in the risk of $\mathrm{HBV}$ reactivation in patients with chronic HBV infection (odds ratio, 0.16 ; $95 \%$ confidence interval, 0.04 to $0.66 ; \mathrm{p}=0.01$ ) (Table 4 ). The absence 
Table 5. Clinical Course of IBD According to Liver Dysfunction

\begin{tabular}{lccc}
\hline Parameter & $\begin{array}{c}\text { Liver dysfunction } \\
\text { positive }(n=14)\end{array}$ & $\begin{array}{c}\text { Liver dysfunction } \\
\text { negative }(n=177)\end{array}$ & p-value \\
\hline IBD flare & $8(57)$ & $53(30))$ & 0.10 \\
IBD related surgery & $5(36)$ & $41(23)$ & 0.56 \\
Hospitalization & $9(64)$ & $58(33)$ & 0.13 \\
\hline
\end{tabular}

Data are presented as the number (\%).

$\mathrm{IBD}$, inflammatory bowel disease.

of hepatitis B surface antibody tended to be associated with liver dysfunction in patients with resolved infection $(0 / 87$ vs $1 / 17, \mathrm{p}=0.075)$.

\section{Management for liver dysfunction}

Patients with liver dysfunction related to HBV reactivation were managed by changing or adding antiviral agents (11/14) or discontinuing anti-TNF- $\alpha$ agents (5/14) and immunomodulators $(1 / 14)$. Normalization of liver function test and virologic response were achieved in 93\% (13/14) and $91 \%(10 / 11)$ of patients, respectively.

\section{Effect of liver dysfunction and antiviral prophylaxis on the disease course of IBD}

The clinical course of IBD remained unaffected by liver dysfunction and antiviral prophylaxis (Tables 5, 6).

\section{DISCUSSION}

To the best of our knowledge, this is the first large-scale study to examine the clinical course of HBV infection and IBD and analyze the risks of liver dysfunction in Asian HBV-infected patients with IBD who were receiving antiTNF- $\alpha$ therapy. In this study, the rate of liver dysfunction due to viral reactivation was $7.3 \%$ after a median time interval of 32.4 months after anti-TNF- $\alpha$ administration. Notably, the liver dysfunction rate in patients with chronic HBV infection was significantly higher (15\%); however, only one patient with a resolved infection experienced liver dysfunction. These results are consistent with previously reported data. Studies on patients with $\mathrm{CD}$ and rheumatoid arthritis, treated with anti-TNF- $\alpha$ agents, have shown that the reactivation rate of pre-existing chronic $\mathrm{HBV}$ infection was $12 \%$ to $39 \% .{ }^{25,26}$ However, according to a meta-analysis of rheumatology cases, the reported $\mathrm{HBV}$ reactivation rate is low $(1.7 \%)$ in patients with resolved infection. ${ }^{27}$ Therefore, we can conclude that anti-TNF- $\alpha$ therapy is associated with a high risk of liver dysfunction due to viral reactivation in Asian IBD patients with chronic HBV infection.

Antiviral therapy significantly reduced liver dysfunction in this study. In patients with chronic HBV infection, liver
Table 6. Clinical Course of IBD According to Antiviral Prophylaxis

\begin{tabular}{lccc}
\hline \multicolumn{1}{c}{ Parameter } & $\begin{array}{c}\text { Prophylaxis } \\
(n=54)\end{array}$ & $\begin{array}{c}\text { No prophylaxis } \\
(n=137)\end{array}$ & p-value \\
\hline IBD flare & $21(39)$ & $40(29)$ & 0.37 \\
IBD related surgery & $19(35)$ & $27(20)$ & 0.07 \\
Hospitalization & $21(39)$ & $46(34)$ & 0.67 \\
\hline
\end{tabular}

Data are presented as the number (\%).

$\mathrm{IBD}$, inflammatory bowel disease.

dysfunction was significantly lower in the antiviral prophylaxis group than in the non-prophylaxis group. However, prophylaxis was not associated with liver dysfunction in patients with resolved infection. Specifically, no liver dysfunction occurred in patients with resolved infection having hepatitis B surface antibodies (0/87), regardless of antiviral prophylaxis. The single patient who experienced liver dysfunction in this group tested negative for hepatitis B surface antibody (1/17). Therefore, antiviral prophylaxis should be considered in chronic HBV infection, although its requirement is less in patients with resolved infection. Recent studies on management strategies for using antiTNF- $\alpha$ drugs have classified patients with resolved and chronic HBV infections into moderate-risk (incidence rate of $\mathrm{HBV}$ reactivation of $1 \%$ to $10 \%$ ) and high-risk (incidence rate $\geq 10 \%$ ) groups for viral reactivation. ${ }^{12,28}$ Our findings further support this treatment-selection approach, and have shown that it can also be applied to IBD patients.

The optimal antiviral prophylaxis strategy for administering anti-TNF- $\alpha$ therapy in IBD is unclear. Several clinical guidelines in gastroenterology have recommended antiviral prophylaxis, ${ }^{16,17}$ although the evidence is not specifically intended for IBD patients. The guidelines are largely based on rheumatology studies, on studies of patients undergoing chemotherapy, or only on reported case series of IBD. ${ }^{14,25,29}$ We believe that the results of this study support the role of antiviral prophylaxis in IBD patients with chronic HBV infection undergoing anti-TNF- $\alpha$ therapy.

Various case reports have revealed that anti-TNF- $\alpha$ agents induced HBV replication with fatal outcomes. ${ }^{25,30}$ Among the 14 subjects who experienced liver dysfunction due to $\mathrm{HBV}$ reactivation in this study, one patient eventually developed hepatic failure. Four patients who experienced liver dysfunction discontinued maintenance anti-TNF- $\alpha$ therapy or immunomodulators used for treating IBD. This interruption in treatment can aggravate the clinical course of IBD. Therefore, antiviral prophylaxis not only prevents fatal reactivation of HBV, but may also indirectly enable the continuation of IBD treatment.

Although screening for HBV before the initiation of immunosuppressive therapy is important, this step is easily 
overlooked. While all IBD patients should undergo screening before starting anti-TNF- $\alpha$ therapy, ${ }^{16,18}$ one study in 2012 that assessed adherence to screening for hepatitis B before the initiation of anti-TNF- $\alpha$ treatment, found that only $25 \%$ of patients were screened; $;{ }^{31}$ the findings validated the need for physician education and awareness regarding this issue.

Generally, it is recommended that antiviral prophylaxis be initiated 2 to 4 weeks before starting anti-TNF- $\alpha$ therapy and continued for at least 6 months after terminating therapy. ${ }^{12,28}$ Entecavir and tenofovir, which have a high barrier to the development of resistance, are recommended as first-line treatments for preventing HBV reactivation; this is because the rate of lamivudine resistance at 1 year is $20 \%$ and increases with continued usage. ${ }^{32,33}$ Indeed, most patients (72\%) who received antiviral prophylaxis in the present study were administered tenofovir or entecavir.

This study has some limitations. Firstly, HBV DNA titers were not checked periodically in all enrolled patients. Therefore, virologic breakthrough, which is essential for defining HBV reactivation, could not be detected in some patients, probably because physicians seemed to be unfamiliar with periodical follow-up using the HBV DNA titer and tended to check the viral status only when abnormalities were observed on the liver function tests. Although we did not detect virologic breakthrough of all patients enrolled in this study, all participants with liver dysfunction were confirmed to have HBV reactivation with a virologic breakthrough. Secondly, this was a retrospective study; therefore, some data may be inaccurate. However, to minimize these inaccuracies, we created a web-based case report form and encouraged researchers to fill in the pertinent findings. Thirdly, the data were hospital-based; therefore, there was a possibility of referral bias. Lastly, as we did not assess the duration of antiviral administration, we could not propose a specific prophylactic strategy.

Nevertheless, the results of the study are meaningful. To the best of our knowledge, this is the first long-term follow-up study utilizing multinational and multicenter data for evaluating liver dysfunction due to viral reactivation, to emphasize the need for antiviral prophylaxis in patients with chronic HBV infection and IBD receiving anti-TNF- $\alpha$ therapy. Further prospective randomized controlled trials are needed to verify the effect of antiviral prophylaxis. However, fatal hepatic failure has been reported in patients with chronic HBV infection, who are not administered antiviral prophylaxis; this makes such trials difficult to conduct.

In conclusion, approximately $7 \%$ of all IBD patients with HBV infection in our study experienced liver dysfunction due to viral reactivation within 3 years of receiv- ing anti-TNF- $\alpha$ agents. Liver dysfunction occurred more frequently in patients with chronic infections than in those with resolved infections. Careful monitoring is needed in such patients, and prophylactic treatment should likewise be administered to prevent viral reactivation, especially in patients with concurrent chronic HBV infection.

\section{CONFLICTS OF INTEREST}

S.J.P. and J.P.I. are editorial board members of the journal but were not involved in the peer reviewer selection, evaluation, or decision process of this article. No other potential conflicts of interest relevant to this article were reported.

\section{ACKNOWLEDGEMENTS}

This work was supported by a grant from the Asian Organization for Crohn's and Colitis.

\section{AUTHOR CONTRIBUTIONS}

Study concept and design: K.M.L., D.B.K. Data acquisition: all authors. Data analysis and interpretation: J.M.L. Drafting of the manuscript; critical revision of the manuscript for important intellectual content: J.M.L., S.C.W., K.M.L., B.D.Y. Statistical analysis: J.M.L. Obtained funding: K.M.L. Administrative, technical, or material support; study supervision: K.M.L., B.D.Y. Approval of final manuscript: all authors.

\section{ORCID}

$\begin{array}{ll}\text { Ji Min Lee } & \text { https://orcid.org/0000-0003-3995-3944 } \\ \text { Shu-Chen Wei } & \text { https://orcid.org/0000-0002-5017-5840 } \\ \text { Kang-Moon Lee } & \text { https://orcid.org/0000-0003-2850-4553 } \\ \text { Byong Duk Ye } & \text { https://orcid.org/0000-0001-6647-6325 } \\ \text { Ren Mao } & \text { https://orcid.org/0000-0002-5523-8185 } \\ \text { Hyun-Soo Kim } & \text { https://orcid.org/0000-0001-7190-0362 } \\ \text { Soo Jung Park } & \text { https://orcid.org/0000-0003-0699-6809 } \\ \text { Sang Hyoung Park https://orcid.org/0000-0002-5366-5749 } \\ \text { Eun Hye Oh } & \text { https://orcid.org/0000-0003-4845-9809 } \\ \text { Jong Pil Im } & \text { https://orcid.org/0000-0003-1584-0160 } \\ \text { Byung Ik Jang } & \text { https://orcid.org/0000-0002-3037-9272 } \\ \text { Dae Bum Kim } & \text { https://orcid.org/0000-0003-0830-3375 } \\ \text { Ken Takeuchi } & \text { https://orcid.org/0000-0002-3483-1801 }\end{array}$




\section{REFERENCES}

1. Ng WK, Wong SH, Ng SC. Changing epidemiological trends of inflammatory bowel disease in Asia. Intest Res 2016;14:111-119.

2. Park SH, Kim YJ, Rhee KH, et al. A 30-year trend analysis in the epidemiology of inflammatory bowel disease in the Songpa-Kangdong district of Seoul, Korea in 1986-2015. J Crohns Colitis 2019;13:1410-1417.

3. Kaibullayeva J, Ualiyeva A, Oshibayeva A, Dushpanova A, Marshall JK. Prevalence and patient awareness of inflammatory bowel disease in Kazakhstan: a cross-sectional study. Intest Res 2020;18:430-437.

4. Lee KM, Jeen YT, Cho JY, et al. Efficacy, safety, and predictors of response to infliximab therapy for ulcerative colitis: a Korean multicenter retrospective study. J Gastroenterol Hepatol 2013;28:1829-1833.

5. Choi CH, Kim YH, Kim YS, et al. Guidelines for the management of ulcerative colitis. Korean J Gastroenterol 2012;59:118-140.

6. Ye BD, Yang SK, Shin SJ, et al. Guidelines for the management of Crohn's disease. Korean J Gastroenterol 2012;59:141-179.

7. Merican I, Guan R, Amarapuka D, et al. Chronic hepatitis B virus infection in Asian countries. J Gastroenterol Hepatol 2000;15:1356-1361

8. Chan HC, Wong VW, Wong GL, Tang W, Wu JC, Ng SC. Prevalence of hepatitis B and clinical outcomes in inflammatory bowel disease patients in a viral-endemic region. BMC Gastroenterol 2016;16:100.

9. Loras C, Gisbert JP, Saro MC, et al. Impact of surveillance of hepatitis B and hepatitis $C$ in patients with inflammatory bowel disease under anti-TNF therapies: multicenter prospective observational study (REPENTINA 3). J Crohns Colitis 2014;8:1529-1538.

10. Kim ES, Cho KB, Park KS, et al. Prevalence of hepatitis-B viral markers in patients with inflammatory bowel disease in a hepatitis-B-endemic area: inadequate protective antibody levels in young patients. J Clin Gastroenterol 2014;48:553558.

11. Ganem D, Prince AM. Hepatitis B virus infection: natural history and clinical consequences. N Engl J Med 2004;350:1118-1129.

12. Loomba R, Liang TJ. Hepatitis B reactivation associated with immune suppressive and biological modifier therapies: current concepts, management strategies, and future directions. Gastroenterology 2017;152:1297-1309.

13. Lucifora J, Xia Y, Reisinger F, et al. Specific and nonhepatotoxic degradation of nuclear hepatitis B virus cccDNA. Science 2014;343:1221-1228.

14. Ryu $\mathrm{HH}$, Lee EY, Shin K, et al. Hepatitis B virus reactivation in rheumatoid arthritis and ankylosing spondylitis patients treated with anti-TNFa agents: a retrospective analysis of 49 cases. Clin Rheumatol 2012;31:931-936.

15. Tamori A, Koike T, Goto H, et al. Prospective study of reactivation of hepatitis $B$ virus in patients with rheumatoid arthritis who received immunosuppressive therapy: evaluation of both HBsAg-positive and HBsAg-negative cohorts. J Gastroenterol 2011;46:556-564.

16. Rahier JF, Magro F, Abreu C, et al. Second European evidence-based consensus on the prevention, diagnosis and management of opportunistic infections in inflammatory bowel disease. J Crohns Colitis 2014;8:443-468.

17. Reddy KR, Beavers KL, Hammond SP, Lim JK, Falck-Ytter YT; American Gastroenterological Association Institute. American Gastroenterological Association Institute guideline on the prevention and treatment of hepatitis B virus reactivation during immunosuppressive drug therapy. Gastroenterology 2015;148:215-219.

18. Farraye FA, Melmed GY, Lichtenstein GR, Kane SV. ACG clinical guideline: preventive care in inflammatory bowel disease. Am J Gastroenterol 2017;112:241-258.

19. Ye BD, Jang BI, Jeen YT, et al. Diagnostic guideline of Crohn's disease. Korean J Gastroenterol 2009;53:161-176.

20. Choi CH, Jung SA, Lee BI, et al. Diagnostic guideline of ulcerative colitis. Korean J Gastroenterol 2009;53:145-160.

21. Satsangi J, Silverberg MS, Vermeire S, Colombel JF. The Montreal classification of inflammatory bowel disease: controversies, consensus, and implications. Gut 2006;55:749753.

22. Terrault NA, Lok ASF, McMahon BJ, et al. Update on prevention, diagnosis, and treatment of chronic hepatitis B: AASLD 2018 hepatitis B guidance. Hepatology 2018;67:1560-1599.

23. Park SH, Yang SK, Lim YS, et al. Clinical courses of chronic hepatitis B virus infection and inflammatory bowel disease in patients with both diseases. Inflamm Bowel Dis 2012;18:2004-2010.

24. Papatheodoridis GV, Manolakopoulos S, Dusheiko G, Archimandritis AJ. Therapeutic strategies in the management of patients with chronic hepatitis B virus infection. Lancet Infect Dis 2008;8:167-178.

25. Esteve M, Saro C, González-Huix F, Suarez F, Forné M, Viver JM. Chronic hepatitis B reactivation following infliximab therapy in Crohn's disease patients: need for primary prophylaxis. Gut 2004;53:1363-1365.

26. Lan JL, Chen YM, Hsieh TY, et al. Kinetics of viral loads and risk of hepatitis B virus reactivation in hepatitis B core antibody-positive rheumatoid arthritis patients undergoing anti-tumour necrosis factor alpha therapy. Ann Rheum Dis 2011;70:1719-1725.

27. Lee YH, Bae SC, Song GG. Hepatitis B virus (HBV) reactivation in rheumatic patients with hepatitis core antigen 
(HBV occult carriers) undergoing anti-tumor necrosis factor therapy. Clin Exp Rheumatol 2013;31:118-121.

28. Park SK, Choi CH, Chun J, et al. Prevention and management of viral hepatitis in inflammatory bowel disease: a clinical practice guideline by the Korean Association for the Study of Intestinal Diseases. Intest Res 2020;18:18-33.

29. Hsu C, Hsiung CA, Su IJ, et al. A revisit of prophylactic lamivudine for chemotherapy-associated hepatitis B reactivation in non-Hodgkin's lymphoma: a randomized trial. Hepatology 2008;47:844-853.

30. Michel M, Duvoux C, Hezode C, Cherqui D. Fulminant hepatitis after infliximab in a patient with hepatitis $\mathrm{B}$ virus treated for an adult onset still's disease. J Rheumatol
2003;30:1624-1625.

31. Vaughn BP, Doherty GA, Gautam S, Moss AC, Cheifetz AS. Screening for tuberculosis and hepatitis B prior to the initiation of anti-tumor necrosis therapy. Inflamm Bowel Dis 2012;18:1057-1063.

32. Lok AS, McMahon BJ. Chronic hepatitis B: update 2009. Hepatology 2009;50:661-662.

33. Zhang MY, Zhu GQ, Shi KQ, et al. Systematic review with network meta-analysis: comparative efficacy of oral nucleos $(t)$ ide analogues for the prevention of chemotherapy-induced hepatitis B virus reactivation. Oncotarget 2016;7:30642-30658. 